Homer CSE, Griffith M, Brodie PM, Kildea S, Curtin A, Ellwood D. (2012) Developing a core competency model and educational framework for primary maternity services: a national consensus approach. Women and Birth 25, 3, pp. 122-122.

\title{
DEVELOPING A CORE COMPETENCY MODEL AND EDUCATIONAL FRAMEWORK FOR PRIMARY MATERNITY SERVICES: A NATIONAL CONSENSUS APPROACH
}

\begin{abstract}
Background: An appropriately educated and competent workforce is crucial to an effective health care system. The National Health Workforce Taskforce (now Health Workforce Australia) and the Maternity Services Inter-Jurisdictional Committee funded a project to develop Core Competencies and Educational Framework for Primary Maternity Services in Australia. These competencies recognise the interdisciplinary nature of maternity care in Australia where care is provided by general practitioners, obstetricians and midwives as well as other professionals.
\end{abstract}

Participants: Key stakeholders from professional organisations and providers of services related to maternity care and consumers of services.

Methods: A national consensus approach was undertaken using consultation processes with a Steering Committee, a wider Reference Group and public consultation.

Findings: A national Core Competencies and Educational Framework for Primary Maternity Services in Australia was developed through an iterative process with a range of key stakeholders. There are a number of strategies that may assist in the integration of these into primary maternity service provider professional groups' education and practice.

Conclusions: The Core Competencies and Educational Framework are based on an interprofessional approach to learning and primary maternity service practice. They have sought to value professional expertise and stimulate awareness and respect for the roles of all primary maternity service providers. The competencies and framework described in this paper are now a critical component of Australian maternity services as they are included in actions in the newly released National Maternity Services Plan and thus have relevance for all providers of Australian maternity services. 


\section{INTRODUCTION}

Maternity services in Australia have received considerable attention recently. ${ }^{1}$ Workforce and education issues have been identified as being central to ensuring access to safe maternity services. Workforce shortages and inequitable geographical distribution, particularly in rural and remote areas, affect the provision of all health services including maternity care. It is important to consider the design of workforce and educational models to address the provision of maternity services. One means to lessen the impact of shortages and distribution problems is to use the skills of the workforce in the most efficient and effective way possible and to develop competency standards to ensure quality. ${ }^{2}$

Currently in Australia, general practitioner (GP) obstetricians, obstetricians and midwives, and are primary carers during childbirth. ${ }^{1,3}$ A range of other health workers may also be involved. Ideally, every provider of maternity care has, at a minimum, a beginning level understanding of the specific health care needs of childbearing women, their babies and families.

In light of these issues, the National Health Workforce Taskforce (NHWT), now known as Health Workforce Australia ${ }^{4}$ sought to develop core competencies and an educational framework for primary maternity services in Australia. This project was to identify the key skills, knowledge, behaviours and attitudes (competencies) required for primary maternity service providers in Australia and develop an Educational Framework to meet these. The development of the Core Competencies and Educational Framework focussed on the main providers of primary maternity services, that is, GP obstetricians, obstetricians and midwives. ${ }^{3}$ The aim of this paper is to describe the consensus development of the Core Competencies and Educational Framework for Maternity Services in Australia.

\section{APPROACH TO DEVELOPMENT}

Initially the Core Competency Model for Primary Maternity Services was developed and then the Educational Framework to inform curricula development for primary maternity service providers and services across Australia was articulated. A Steering Committee and Reference Group were established. These groups represented a wide range of professional colleges, organisations and consumers involved in maternity services across Australia.

\section{Core Competency Model}

The starting point was the Primary Maternity Services Framework. ${ }^{3}$ This takes an interprofessional approach and views childbirth as a normal and significant physiological event in which women and their babies have individual needs. The aim of a primary maternity model is to offer safe and effective care for women with normal pregnancy risk.

A systematic literature search (2004-2008) related to competencies for the three main professional groups (GP obstetricians, obstetricians, midwives) and others involved in maternity care in Australia was undertaken. The main databases used were CINAHL and Medline. Information was also drawn from the Cochrane Collaboration and other sites providing interprofessional education. A search of the Australian Government and Government Agency 
websites was also undertaken. The focus was on the identification of key skills, knowledge, behaviours and attitudes (competencies or capabilities) to inform the development of a competency model for primary maternity services across remote, rural and urban Australia.

The websites of professional maternity organisations were searched for relevant documents and information. Figure 1 provides a list of the professional maternity organisations that were included.

A number of specific documents were retrieved and used as a basis for the project. These included:

- $\quad$ RDAA - The National Consensus Framework for Rural Maternity Services ${ }^{5}$

- AHMAC - Primary Maternity Services Framework for Implementation ${ }^{3}$

- ACSQHC - National Patient Safety Education Framework ${ }^{6}$

- ANMC - National Competency Standards for the Midwife ${ }^{7}$

- ANMC - National Competency Standards for the Nurse Practitioner ${ }^{8}$

- Department of Human Services, Victoria - Competency Standards for health and allied health professionals in Australia report ${ }^{9}$

- NATSIHC, National Strategic Framework for Aboriginal and Torres Strait Islander Health Context ${ }^{10}$

- Royal College of Physicians and Surgeons of Canada - CanMED Proficiencies ${ }^{11}$

\section{Educational Framework}

The Educational Framework was developed through a search of evidence relating to curriculum for maternity services, accreditation frameworks for maternity education and courses, and educational frameworks in health.

Documents related to midwifery and medical regulation, undergraduate, postgraduate and postregistration education standards and frameworks were sourced. These included RANZCOG, RACGP, Australian Medical Association (AMA), Australian College of Rural and Remote Medicine (ACRRM), Council of Deans of Nursing and Midwifery (CDNM), Centre for Postgraduate Medical Education (CPME) Medical Deans of Australia and New Zealand (MDANZ), World Health Organization (WHO), International Federation of Gynaecology and Obstetrics (FIGO), ICM, National Health Service (UK), National Health Service (Scotland), Australian Council for Safety and Quality in Healthcare (ACSQHC) and ANMC as well as the Nursing and Midwifery Registration Authority (NMRA) for each state and territory.

\section{DEVELOPING THE MODEL AND FRAMEWORK}

\section{Core Competency Model}

The project identified a small number of published competency standards however, no nationally agreed format for competency standards exists. ${ }^{9}$. Most health and allied health professions have competency standards or are in the process of developing them. ${ }^{12}$ The majority of competency standards had been developed for the midwifery, nursing and the public health workforce. Competencies within these documents focussed on knowledge, legal and professional 
responsibilities, communication, reflection, self appraisal and management and leadership. Specific clinical skills were rarely included in these documents. It was decided not to add these as it was felt this would limit the capacity of the competencies to be multidisciplinary and there were concerns about the competencies being used a checklist of 'skills' rather than an overall level of competence which includes attitudes and behaviours.

Each of the competency standards reviewed had an organised framework/format commonly organised into broad modules or clusters of competence reflecting specific areas of practice. These clusters or modules were defined into competency elements representing individual tasks, behaviours or attitudes underlying specific aspects of professional performance. These were further articulated through examples of competent performance for each competency element and identified as either performance criteria or cues.

Four domains were developed to form the basis of the Core Competency Model (Figure 2). These were: woman centred care; professionalism, workplace and communication.

\section{Educational Framework}

The Educational Framework identifies suggested learning areas, objectives and assessment elements as components for curricula relevant to the undergraduate, postgraduate, continuing professional development, up skilling or return to practice learning needs of primary maternity service providers - particularly doctors and midwives.

There were competency standards and/or educational standards for a number of different disciplines. A number of standards for education programs had similar criteria for accreditation. The similarities included the requirements for core curriculum content to address relevant national professional competency standards, demonstrate an incremental process of learning and a commitment to lifelong learning. The emphasis of most curriculum documents was the development of skills for critical self reflection, the integration of theoretical and clinical components appropriate to the professional practice role, the roles and context of professional practice and the development of knowledge, skills and professional qualities commensurate with the profession.

\section{Defining the learning principles}

A number of general educational principles were identified. They contributed to the content and structure of the Educational Framework and included:

- Primary maternity service providers are adult learners;

- Interprofessional learning ensures the best outcomes for women and their babies

- Learning is lifelong, based in clinical practice situations and includes formal education, continuing professional development and informal learning experiences

- Adult learners take responsibility for their own learning and invest time, money and effort in training or education.

The structure of two national frameworks, the Committee of Deans of Australian Medical 
School's (CDAMS) Indigenous Health Curriculum Framework ${ }^{13}$ and the Australian Commission on Safety and Quality in Healthcare's (ACSQHC) National Patient Safety Education Framework $^{14}$ offered useful guidance to the development of the Educational Framework. The structure of the Educational Framework combined aspects of these two frameworks by identifying suggested learning areas, objectives and assessment elements as components for curricula relevant to the undergraduate, postgraduate, continuing professional development, up skilling or return to practice learning needs of primary maternity service providers.

The Competency Model and Framework were linked. Within each Domain, Learning/Subject Areas were created and these reflected the Sub-Domains of the Competency Model. For each Learning Area, one or more Learning Objectives were developed. To meet the requirements of these objectives and to enable measured outcomes, Performance Elements/Outcomes that reflect the Competency Elements complete the Framework.

\section{Consultation Process}

Consultations occurred during each part of the project, initially with the Steering Committee and the Reference Group. Review and revision of the draft documents occurred a number of times. The Steering Committee and Reference Group were invited to circulate the documents to their members for feedback. One of the key points of feedback centred on the potential value in fostering greater collaboration between doctors and midwives.

The project sought feedback from consumers, maternity service providers, education providers, government representatives, managers, academics and others with an interest in competencies and education for primary maternity services in Australia. The purpose of this consultation process was to engage with as many stakeholders as possible. A range of organisations and groups/committees participated in the online survey $(n=69)$. Some were formal organisations while others were networked groups or committees.

The Framework document was mailed to the relevant regulatory authorities for their comments and review. The authorities were the Australian Medical Council (AMC), the Nursing and Midwifery Regulatory Authorities in every state and territory and the Australian Nursing and Midwifery Council (ANMC). The feedback was positive and centred around altering some terminology as well as strengthening some of the subject areas such as breastfeeding, perinatal mental health and wellness, and communication. This feedback helped shape the final Core Competencies and Educational Framework document. Figure 3 presents an example of one domain. As there are 14 competency standards such as this, only one is included here by way of an example.

\section{DISCUSSION}

Maternity services can be challenging to provide in a context of workforce shortages and a lack of understanding or consistency about the competencies required for effective provision of care. Developing national consistency and a commitment to interdisciplinary learning and working together may be an important step forwards. However, it is important to develop broad principles to achieve this rather than prescriptive approaches that may not suit all contexts or groups. 
The Core Competencies and Educational Framework for Primary Maternity Services were developed through a national consensus approach. They are based on principles of service provision rather than specific tasks for individual professional groups. They are not intended to reduce maternity care to a single list of skills and tasks that could be undertaken by any individual. They are aimed to enhance collaboration between the professionals who provide primary maternity services, that is, care for women of 'normal risk' across the continuum of antenatal, birthing and postnatal period. An interprofessional approach to learning and primary maternity service practice is a core component of this work. The competencies and educational framework value professional expertise and it is hoped will stimulate an awareness and respect for the different roles of primary maternity service providers as well as confidence in the providers to work together to achieve the best outcomes for mothers and their babies.

The competencies and framework described in this paper are now a critical component of Australian maternity services. The newly released National Maternity Services Plan ${ }^{15}$ has an aim to facilitate a culture of interdisciplinary collaboration in maternity care and one of the signs of success in the Plan is that "agreed actions arising from the Core Competencies and Educational Framework for Primary Maternity Services Final Report are implemented” (page 48).

The competencies and framework are designed to be used to be in their entirety. However for some provider groups and disciplines, different aspects may be more relevant. The competency standards, elements, learning objectives and performance outcomes could be addressed in the development of education programs for these groups. Education providers are encouraged to consider how the components of the Framework might best fit within their specific program.

Processes for assisting with curricula development or review are identified. These are broad as the aim was not to identify a common curriculum per se. More importantly, the interprofessional learning principles that underpin the Framework could be incorporated into all educational programs, at entry to practice, as part of continuing professional development or re-entry to practice program. The learning objectives and the performance elements/outcomes in the Framework could be the starting point in the development of the program content, design of the delivery mode and the assessments. The content delivered to primary maternity services providers depends upon the context, participants and timeframe. For example, the content in an undergraduate program for midwives will differ from the content provided to GPs studying obstetrics at postgraduate level or obstetricians undertaking specialist programs. There will also be differences in content at entry to practice level compared with continuing professional development.

Despite developing competency standards, we recognise that there are challenges in assessing competence. Education providers, at undergraduate, postgraduate and continuing professional development levels, have a range of strategies to undertake assessment and these should be utilised as appropriate. ${ }^{16}$ The ways in which assessments are reflected in curricula depends on the context which may differ depending upon whether the learners are undergraduate, postgraduate, current practising professionals or those seeking re-entry to practice. In some situations this will be episodic and/or formative, that is occurring at regular planned intervals and/or through an undergraduate or specialist postgraduate program. Assessment strategies must create 
opportunities for learners to see what they have done well, what they have not done as well and how improvements could be made. ${ }^{16}$ Assessments should relate to the achievement of the competencies which in this case are reflected in the learning outcomes.

The assessment of competencies in the workplace is an important area that is still developing and may increase with initiatives such as Health Workforce Australia. Competency-based assessment is largely activity-based and practical. ${ }^{17}$ The role of assessment is not to reduce skills, attitudes or knowledge to a single element as competence implies that an individual demonstrates an understanding of the knowledge that is the basis of the practical task being carried out and the attitudes or behaviours to provide quality care ${ }^{17}$ Importantly, assessment strategies must be aligned with the competencies which aim to meet the needs of women in primary maternity services. In the Core Competencies and Educational Framework, this can be done by linking the competencies with the learning outcomes and then developing assessment strategies to address each one. Depending on the context and utility, assessment tools will vary according to levels of achievement as it must be considered that each primary maternity service provider will have different learning needs and styles of learning at different levels of skill acquisition as they develop and achieve the primary maternity service competencies. ${ }^{13}$ Future work may look at the development of common assessment tools using the components of the education framework to work towards national consistency. Other future research includes the need to explore opportunities for integration or incorporation of the current competency standards for maternity professionals, for example, those for midwives, ${ }^{7}$ into the Core Competencies and Educational Framework. Other developments currently within the national regulation and accreditation processes will also need consideration.

\section{CONCLUSION}

Addressing workforce and education issues such as human resource shortages and geographical distribution particularly in rural and remote areas are central to ensuring access to safe maternity services for Australian women and families. Utilising the skills of the existing workforce in the most efficient and effective way possible is an important workforce stratregy. ${ }^{2}$ Effective utilisation will depend on effective collaboration and an understanding of the roles and competencies of the services. The Core Competencies and Educational Framework are based on an interprofessional approach to learning and primary maternity service practice. They have sought to value professional expertise and stimulate awareness and respect for the roles of all primary maternity service providers. 


\section{REFERENCES}

1. Department of Health and Ageing. Improving Maternity Services in Australia: The Report of the Maternity Services Review. Canberra: Australian Government, 2009.

2. Productivity Commission. Australia's Health Workforce, Research Report. Canberra: Australian Government, 2005.

3. Australian Health Ministers' Advisory Council. Primary Maternity Services in Australia; A framework for implementation. Canberra: NSW Department of Health on behalf of the Maternity Services Inter-jurisdictional Committee, 2008.

4. Health Workforce Australia. 2010. (accessed 9 August, 2010, at http://www.hwa.gov.au/.)

5. Rural Doctors Association of Australia. National Consensus Framework for Rural Maternity Services. Canberra: Rural Doctors Association of Australia, 2008.

6. Australian Council for Safety and Quality in Healthcare. National Patient Safety Education Framework. Canberra: Australian Council for Safety and Quality in Healthcare, 2005.

7. Australian Nursing and Midwifery Council. National Competency Standards for the Midwife. Canberra: Australian Nursing and Midwifery Council, 2006.

8. Australian Nursing and Midwifery Council. National Competency Standards for the Nurse Practitioner. Canberra: Australian Nursing and Midwifery Council, 2006.

9. Community Services \& Health Industry Training Board. Competency Standards for Health and Allied Health Professionals in Australia. Melbourne: Department of Human Services (Victoria), 2005.

10. National Aboriginal Community Controlled Health Organisation. National Strategic Framework for Aboriginal and Torres Strait Islander Health Context Canberra: National Aboriginal Community Controlled Health Organisation, 2003.

11. Frank J, Jabbour M, Tugwell P, et al. CanMEDS 2000 Project: Skills for the new millennium: Report of the societal needs working group. Ann Roy Coll Phys Surg Can, 1996; 29: 206-216.

12. Department of Human Services Victoria. Competency Standards for Health and Allied Health Professionals in Australia, Research Report. Melbourne: Victorian Community Services and Health Industry Training Board Inc., 2005.

13. Committee of Deans of Australian Medical Schools. CDAMS Indigenous Health Curriculum Framework. Melbourne: University of Melbourne, 2004.

14. Australian Council for Safety and Quality in Health Care. Open Disclosure Standard: A National Standard for Open Communication in Public and Private Hospitals, Following an Adverse Event in Health Care. Canberra: Australian Council for Safety and Quality in Health Care, 2003.

15. Australian Health Ministers Conference. National Maternity Services Plan. Canberra: Commonwealth of Australia, 2011.

16. Preston B. ANMC National Framework for Accreditation of Nursing \& Midwifery Courses. Canberra: Australian Nursing and Midwifery Council, 2007.

17. World Health Organization. WHO European Strategy for Continuing Education for Nurses and Midwives, WHO Europe Midwifery Curriculum for Qualified Nurses. Geneva: World Health Organization, 2003. 
Figure 1: The professional maternity organisations that were included in the literature search

Australian College of Midwives (ACM)

Royal Australian and New Zealand College of Obstetricians and Gynaecologists (RANZCOG), Royal Australian College of General Practitioners (RACGP)

Rural Doctors Association of Australia (RDAA)

National Association of Specialist Obstetricians and Gynaecologists (NASOG)

Australian Nursing and Midwifery Council (ANMC)

Royal College of Obstetricians and Gynaecologists (RCOG)

Royal College of Physicians and Surgeons of Canada

New Zealand College of Midwives (NZCOM)

International Confederation of Midwives (ICM)

Health Professional Registering Authorities and international organisations such as the Centre for the Advancement of Interprofessional Education (UK) 
Figure 2: Core Competency Model Domains and Sub Domains

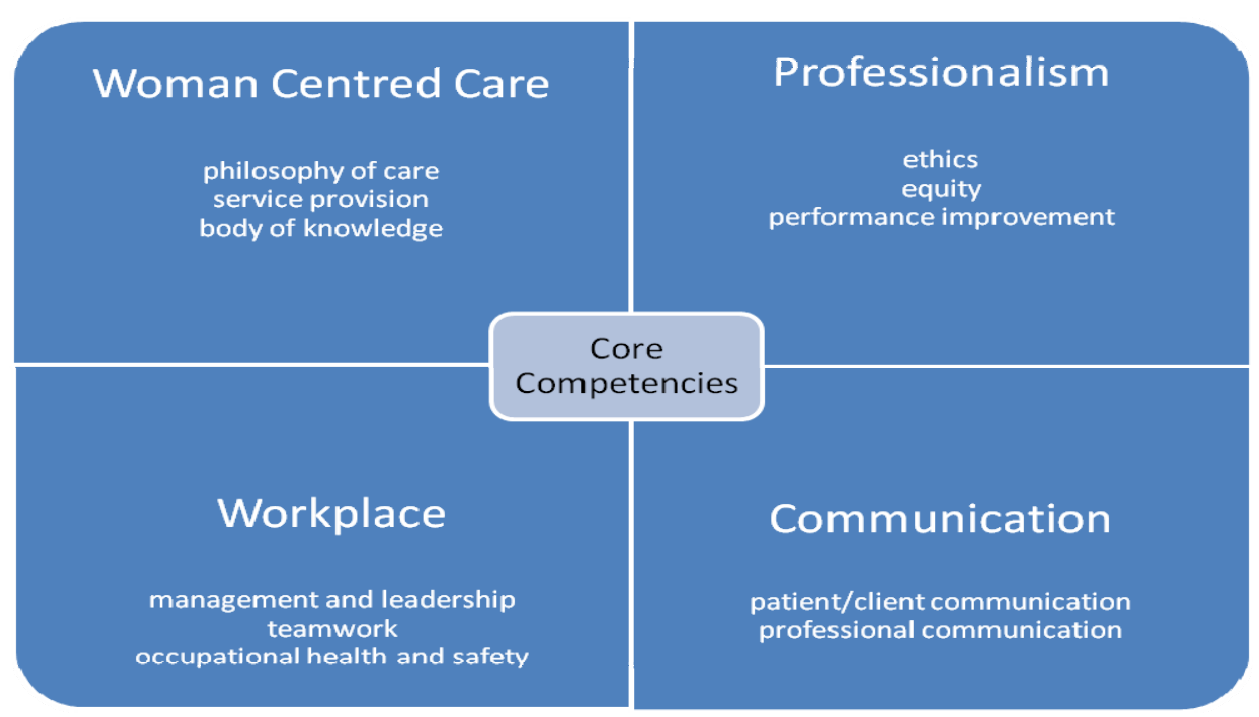

Page $\mid 10$ 
Figure 3: An example of the Core Competencies and Educational Framework for Maternity Services

\begin{tabular}{|c|c|}
\hline \multicolumn{2}{|c|}{ Domain 4: COMMUNICATION } \\
\hline \multicolumn{2}{|c|}{ Sub-Domain and Learning/Subject Area - WOMAN CENTRED COMMUNICATION } \\
\hline Competency Standard & $\begin{array}{l}\text { 14. Engages in effective, appropriate communication to ensure optimal maternal and newborn } \\
\text { health outcomes. }\end{array}$ \\
\hline Competency Elements & $\begin{array}{l}\text { Knowledge } \\
\text { Knows a range of interpersonal communication principles and processes including adult } \\
\text { learning. } \\
\text { - } \text { Identifies barriers to effective communication. } \\
\text { Skills } \\
\text { - Communicates effectively with the woman and her family using language that is readily } \\
\text { - Legibly documents decisions, actions and outcomes. } \\
\text { - Adapts communication to the needs of and a level suited to the individual woman. } \\
\text { Attitude } \\
\text { - Conveys a calm, confident and approachable manner. }\end{array}$ \\
\hline $\begin{array}{l}\text { Learning Objectives - } \\
\text { The Primary Maternity } \\
\text { Service Provider (PMSP) } \\
\text { will... }\end{array}$ & $\begin{array}{l}\text { 14A. engage in effective woman centred communication to ensure optimal maternal and newborn } \\
\text { health outcomes. }\end{array}$ \\
\hline $\begin{array}{l}\text { Performance } \\
\text { Elements/Outcomes }\end{array}$ & $\begin{array}{l}\text { - Responds in a calm, confident and approachable manner when communicating with the } \\
\text { woman and her family. } \\
\text { - Uses a range of interpersonal communication principles and processes and adapts } \\
\text { communication to the needs of and a level suited to the individual to communicate effectively } \\
\text { with the woman and her family. } \\
\text { - Recognises and addresses barriers to effective communication by fully utilising resources } \\
\text { that promote and enhance understanding i.e. culturally appropriate information, resources } \\
\text { and healthcare interpreters. } \\
\text { - Legibly and concurrently documents decisions, actions and evaluation of outcomes. }\end{array}$ \\
\hline
\end{tabular}

